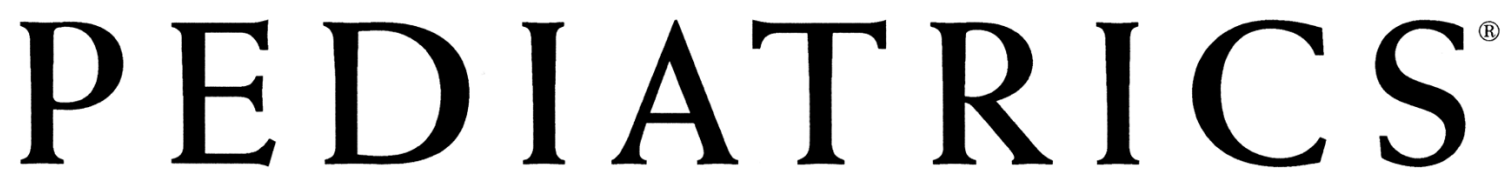

OFFICIAL JOURNAL OF THE AMERICAN ACADEMY OF PEDIATRICS

\title{
Clinical Features That Identify Children With Primary Immunodeficiency Diseases
}

Anbezhil Subbarayan, Gloria Colarusso, Stephen M. Hughes, Andrew R. Gennery, Mary Slatter, Andrew J. Cant and Peter D. Arkwright

Pediatrics published online Apr 11, 2011;

DOI: $10.1542 /$ peds.2010-3680

The online version of this article, along with updated information and services, is located on the World Wide Web at:

http://www.pediatrics.org

PEDIATRICS is the official journal of the American Academy of Pediatrics. A monthly publication, it has been published continuously since 1948. PEDIATRICS is owned, published, and trademarked by the American Academy of Pediatrics, 141 Northwest Point Boulevard, Elk Grove Village, Illinois, 60007. Copyright ( 2011 by the American Academy of Pediatrics. All rights reserved. Print ISSN: 0031-4005. Online ISSN: 1098-4275.

\section{American Academy of Pediatrics}

DEDICATED TO THE HEALTH OF ALL CHILDREN ${ }^{m}$ 


\section{Clinical Features That Identify Children With Primary Immunodeficiency Diseases}

WHAT'S KNOWN ON THIS SUBJECT: Children with severe, recurrent, or unusual infections may have an underlying primary immunodeficiency disease (PID). Ten warning signs have been promoted by patient support groups to help identify children with PID, but the signs have never been tested in a rigorous scientific study.

WHAT THIS STUDY ADDS: Family history, intravenous antibiotics for sepsis, and failure to thrive predict at least $89 \%$ of children with T-lymphocyte, complement, and neutrophil PID. B-lymphocyte PID are more difficult to diagnose from the clinical features, and a lower threshold is required for assessing antibody levels.

\section{abstract}

BACKGROUND: The 10 warning signs of primary immunodeficiency diseases (PID) have been promoted by various organizations in Europe and the United States to predict PID. However, the ability of these warning signs to identify children with PID has not been rigorously tested.

OBJECTIVE: The main goal of this study was to determine the effectiveness of these 10 warning signs in predicting defined PID among children who presented to 2 tertiary pediatric immunodeficiency centers in the north of England.

METHODS: A retrospective survey of 563 children who presented to 2 pediatric immunodeficiency centers was undertaken. The clinical records of 430 patients with a defined PID and 133 patients for whom detailed investigations failed to establish a specific PID were reviewed.

RESULTS: Overall, $96 \%$ of the children with PID were referred by hospital clinicians. The strongest identifiers of PID were a family history of immunodeficiency disease in addition to use of intravenous antibiotics for sepsis in children with neutrophil PID and failure to thrive in children with T-lymphocyte PID. With these 3 signs, $96 \%$ of patients with neutrophil and complement deficiencies and $89 \%$ of children with T-lymphocyte immunodeficiencies could be identified correctly. Family history was the only warning sign that identified children with B-lymphocyte PID.

CONCLUSIONS: PID awareness initiatives should be targeted at hospital pediatricians and families with a history of PID rather than the general public. Our results provide the general pediatrician with a simple refinement of 10 warning signs for identifying children with underlying immunodeficiency diseases. Pediatrics 2011;127:810-816
AUTHORS: Anbezhil Subbarayan, MBBS, ${ }^{a}$ Gloria Colarusso, MB BS, ${ }^{b}$ Stephen M. Hughes, MB, PhD, ${ }^{a}$

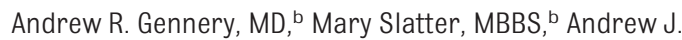
Cant, MD, ${ }^{\mathrm{b}}$ and Peter D. Arkwright, MB, DPhila

aDepartment of Paediatric Allergy and Immunology, University of Manchester, Royal Manchester Children's Hospital, Manchester, United Kingdom; and ${ }^{b}$ Supraregional Paediatric Immunology Center, University of Newcastle, Royal Victoria Infirmary, Newcastle Upon Tyne, United Kingdom

\section{KEY WORDS}

primary immunodeficiency disease, infection, children, diagnosis, family history

\section{ABBREVIATIONS}

PID—primary immunodeficiency disease

SCID—severe combined immunodeficiency disease

Dr Arkwright conceived of the study; Drs Subbarayan, Colarusso, Gennery, and Arkwright helped with the collection and analysis of the data; and all the authors critically reviewed and revised the manuscript and approved the final version.

www.pediatrics.org/cgi/doi/10.1542/peds.2010-3680

doi:10.1542/peds.2010-3680

Accepted for publication Jan 27, 2011

Address correspondence to Peter D. Arkwright, MB, DPhil, Department of Paediatric Allergy and Immunology, Royal Manchester Children's Hospital, University of Manchester Oxford Road, Manchester M13 9WL, United Kingdom. E-mail: peter.arkwright@nhs.net

PEDIATRICS (ISSN Numbers: Print, 0031-4005; Online, 1098-4275) Copyright (c) 2011 by the American Academy of Pediatrics FINANCIAL DISCLOSURE: The authors have indicated they have no financial relationships relevant to this article to disclose. 
The prevalence of primary immunodeficiency diseases (PID) in Europe and in the United States is quoted as 1 per 10000 and 20000 , respectively. ${ }^{1,2}$ An increasing number of PID have been identified, which can predispose to life-threatening infectious diseases particularly if the diagnosis is delayed in the most severe conditions (eg, severe combined immunodeficiency diseases [SCID]). 3,4 Identification of most children with primary immunodeficiencies relies on the awareness of families and their physicians of PID and a high index of suspicion leading to prompt referral to specialists trained in the management of these complex diseases. Patient support groups such as the National Primary Immunodeficiency Resource Center in the United States and the Primary Immunodeficiency Association in the United Kingdom, as well as specialists, are currently promoting the use of 10 warning signs of primary immunodeficiency to help with the diagnosis of PID. ${ }^{5,6}$ The development of these warning signs by the Jeffrey Model Foundation was based on expert opinion, and there is currently little or no population-based evidence to support their general use. We therefore investigated the presenting symptoms of children referred to 2 pediatric immunology units in northern England to determine which warning signs were most helpful in identifying children with defined PID. The primary aim of the study was to produce a simple, evidence-based schema for the identification of children with potentially life-threatening immune disorders. It is suggested that heightened awareness by the general public and physicians is required if PID are to be diagnosed in a more timely fashion. ${ }^{5}$ The second aim of this study was to determine where awareness campaigns should most effectively be targeted.

\section{METHODS}

The clinical records of 430 children who presented with specific diagnoses of PID to the regional pediatric immunology centers at Royal Manchester Children's Hospital in Manchester and Newcastle General Hospital in Newcastle on Tyne over the last decade were reviewed. Special note was made of the children's presenting symptoms in relation to the 10 warning signs of PID currently promoted by the National Primary Immunodeficiency Resource Center, 5 as well as routine demographic data. A total of 133 children who presented sequentially to the regional pediatric immunology center in Manchester during the same period with severe, unusual, or recurrent infections but in whom investigations failed to reveal an underlying PID were used for comparative purposes. Because no patient or physician involvement was involved in this survey and there were no perceived ethical issues, research ethics approval was not required.

The most current version of the 10 warning signs developed by the Jeffrey Model Foundation Medical Advisory Board used for comparative purposes in this study are:

1. $\geq 4$ new ear infections within 1 year;

2. $\geq 2$ serious sinus infections within 1 year;

3. $\geq 2$ months of oral antibiotic treatment with little effect;

4. $\geq 2$ episodes of pneumonia within 1 year;

5. failure of an infant to gain weight or grow normally;

6. recurrent, deep skin or organ abscesses;

7. persistent thrush in mouth or fungal infection on skin;

8. need for intravenous antibiotics to clear infections;
9. $\geq 2$ deep-seated infections, including septicemia; and

10. a family history of PID.

Patients' clinical data were entered into an SPSS program for statistical analysis (SPSS version 17, SPSS Inc, Chicago, IL). $\chi^{2}$ tests and logistic regression analysis were used to determine statistical differences between groups.

\section{RESULTS}

\section{Demographic Characteristics and Distribution of PID Within the Cohort}

Clinical records were reviewed of 430 children, 333 in Manchester and 230 in Newcastle, in whom defined PID had been identified. Details of the PID diagnoses are listed in Table 1 and include 74 children with neutrophil or monocytic PID, 92 children with B-lymphocyte PID, 22 with complement PID, and 242 with T-lymphocyte PID. The characteristics of the overall cohort of 563 children, including the 133 controls, are shown in Table 2. Only 27 (5\%) were referred from primary care; the rest were from hospital specialists, equally split between general pediatricians $(51 \%)$ and tertiary specialists (49\%). Overall, $16 \%$ of children with no definable PID, and $15 \%$ with neutrophil or monocytic PID and 20\% with B-lymphocyte PID were Asians (from Pakistan) compared with $38 \%$ of children with T lymphocyte and $36 \%$ with complement PID, in keeping with the autosomal recessive inheritance patterns of many of these PID and the high consanguinity rates in this ethnic group. ${ }^{14}$

The age of onset of symptoms correlated with what is known about the age of presentation for different PID. B-lymphocyte and complement PID presented in late infancy and early childhood. In contrast, T-lymphocyte PID presented at a median age of 1 
TABLE 1 PID Subtypes Within the Cohort

\begin{tabular}{|c|c|c|c|}
\hline Neutrophil or Monocytic $(N=74)$ & B Lymphocyte $(N=92)$ & $\begin{array}{l}\text { Complement } \\
(N=22)\end{array}$ & T Lymphocyte $(N=242)$ \\
\hline Severe congenital neutropenia (15) & $\begin{array}{l}\text { Agammaglobulinemia, including } \\
\text { Bruton's (27) }\end{array}$ & Factor 1q (4) & $\begin{array}{l}\text { Severe combined immunodeficiency (recombinase activating } \\
\text { gene, common } \gamma \text { chain, adenosine deaminase/purine } \\
\text { nucleoside phosphorylase, interleukin-7 receptor } \alpha \text { chain, } \\
\text { Janus kinase } 3 \text {, MHC class II, reticular dysgenesis) (133) }\end{array}$ \\
\hline $\begin{array}{l}\text { Chronic granulomatous } \\
\text { disease (38) }\end{array}$ & Common variable immunodeficiency (45) & Factor 2 (7) & CD40 ligand deficiency (13) \\
\hline Specific granule deficiency (2) & Selective antibody deficiency (17) & Factor $3(3)$ & $\begin{array}{l}\text { DNA repair (Nijmegen breakage syndrome, ataxia telangiectasia, } \\
\text { ligase IV, Cernunnos, Artemis) (10) }\end{array}$ \\
\hline $\begin{array}{l}\text { Leukocyte adhesion } \\
\text { defect (6) }\end{array}$ & $\begin{array}{l}\text { Immunodeficiency, centromere } \\
\text { instability, and facial anomalies } \\
\text { syndrome (3) }\end{array}$ & Factor 6 (2) & T-cell activation (24) \\
\hline $\begin{array}{l}\text { Toll-like receptor pathway } \\
\text { defect (3) }\end{array}$ & - & Factor 7 (2) & Wiskott-Aldrich syndrome/dedicator of cytokinesis 8 (16) \\
\hline \multirow{2}{*}{$\begin{array}{l}\text { Autosomal dominant hyper lgE } \\
\text { syndrome (10) }\end{array}$} & - & Factor I (4) & 22q11 microdeletion (33) \\
\hline & - & - & $\begin{array}{l}\text { Miscellaneous (cartilage hair hypoplasia, MHC class I, } \\
\text { transmembrane activator, CAML interactor) (13) }\end{array}$ \\
\hline
\end{tabular}

Values in parentheses are $n$. IgE indicates immunoglobulin E; CAML, calcium-modulating cyclophilin ligand.

TABLE 2 Demographic Information Relating to Whether Children Had a Definable PID and the PID Category

\begin{tabular}{|c|c|c|c|c|c|c|}
\hline & $\begin{array}{l}\text { No Definable PID } \\
\qquad(N=133)\end{array}$ & $\begin{array}{l}\text { Definable PID } \\
\qquad(N=430)\end{array}$ & $\begin{array}{l}\text { Neutrophil } \\
\quad(N=74)\end{array}$ & $\begin{array}{l}\text { B Lymphocyte } \\
\qquad(N=92)\end{array}$ & $\begin{array}{l}\text { Complement } \\
\qquad(N=22)\end{array}$ & $\begin{array}{l}\text { T Lymphocyte } \\
(N=242)\end{array}$ \\
\hline Referrals from primary care, $n(\%)$ & $9(7)$ & $18(4)$ & $2(6)$ & $11(15)$ & $2(17)$ & $3(4)$ \\
\hline $\begin{array}{l}\text { Age of onset of symptoms, median } \\
\text { (interquartile range), mo }\end{array}$ & $9(3-24)$ & $3(1-11)$ & $4(2-16)$ & $10(3-24)$ & $15(10-63)$ & $1(1-4)$ \\
\hline $\begin{array}{l}\text { Delay from initial symptoms to referral, } \\
\text { median (interquartile range), mo }\end{array}$ & $24(12-42)$ & $6(1-32)$ & $19(2-64)$ & $20(6-67)$ & $56(0-134)$ & $3(1-15)$ \\
\hline Deaths, $n(\%)$ & $1(1)$ & $18(4)$ & $3(4)$ & 0 & $1(5)$ & $14(6)$ \\
\hline Asian (Pakistani) ethnicity, $n$ (\%) & $21(16)$ & $130(30)$ & $11(15)$ & $18(20 \%)$ & $8(36)$ & $93(38)$ \\
\hline $\begin{array}{l}\text { Current age of patients, median } \\
\text { (interquartile range), y }\end{array}$ & $9(7-12)$ & $9(5-15)$ & $10(5-16)$ & $12(8-16)$ & $15(10-18)$ & $8(4-13)$ \\
\hline Male gender, \% & 56 & 65 & 73 & 67 & 68 & 60 \\
\hline
\end{tabular}

Discrete data are given as number (percentage); continuous data are given as median (interquartile range).

month, and neutrophil PID also presented early in infancy. Children who had the most severe T-lymphocyte immunodeficiencies (ie, SCID) presented at a median age of 1 month (IQR: $0-3$ ) and the time from first symptoms to diagnosis was only 1 month (IQR: $0-4)$. Children with T-cell immunodeficiencies at the less severe end of the spectrum had a later onset of symptoms (3 months [IQR: 1-12]), and the delay in making the diagnosis was proportionally longer at 18 months (IQR: 5-36).

\section{Frequency of the 10 Warning Signs in Children With PID}

The proportion of children with each of the 10 warning signs is shown in Table 3. A family history was present in one- third of children with PID, compared with only $4 \%$ of children in whom no PID was found; two-thirds of children with complement deficiencies had a positive family history. Compared with children with no definable PID, deepseated infections and pneumonias were not more common in children with PID. Although failure to thrive was significantly more common, recurrent otitis media and sinus infections were significantly less common in patients with T-lymphocyte and neutrophil PID. Deep skin or organ abscesses were largely a problem in patients with neutrophil PID and persistent thrush largely confined to children with T-lymphocyte PID. Although approximately half of all children in the cohort had been given intravenous antibiotics for sepsis, the percentage was significantly higher (82\%) in those with neutrophil PID. Before diagnosis, prolonged courses of oral antibiotics were often prescribed to children with defined PID.

\section{Warning Signs Most Predictive of PID}

The strongest identifier of PID was a family history of immunodeficiency disease, defined as physiciandiagnosed PID in a family member. Overall, a family history was 18-fold more common in children with PID than those without definable PID (Table 4). Once family history had been accounted for, the 2 most helpful warning signs were use of intravenous an- 
TABLE 3 Proportion of Children With the 10 Warning Signs Grouped According to PID Type

\begin{tabular}{|c|c|c|c|c|c|c|}
\hline & $\begin{array}{l}\text { No Definable PID } \\
(N=133), n(\%)\end{array}$ & $\begin{array}{c}\text { Definable PID } \\
(N=430), n(\%)\end{array}$ & $\begin{array}{c}\text { Neutrophil } \\
(N=74), n(\%)\end{array}$ & $\begin{array}{l}\text { B Lymphocyte } \\
(N=92), n(\%)\end{array}$ & $\begin{array}{c}\text { Complement } \\
(N=22), n(\%)\end{array}$ & $\begin{array}{c}\text { T Lymphocyte } \\
(N=242), n(\%)\end{array}$ \\
\hline Positive family history & $6(4)$ & $148(34)^{\mathrm{a}}$ & $31(42)^{a}$ & $24(26)^{a}$ & $14(64)^{\mathrm{a}}$ & $79(33)^{\mathrm{a}}$ \\
\hline$\geq 2$ deep-seated infections & $15(11)$ & $44(10)$ & $10(14)$ & $8(9)$ & $6(27)$ & $20(8)$ \\
\hline$\geq 2$ episodes of pneumonia & $34(26)$ & $105(24)$ & $19(26)$ & $34(37)$ & $2(9)$ & $50(21)$ \\
\hline Abscesses (deep skin or organ) & $9(7)$ & $56(13)$ & $41(56)^{\mathrm{a}}$ & $2(2)$ & $1(4)$ & $12(5)$ \\
\hline Multiple acute otitis media & $47(35)$ & $64(15)^{\mathrm{a}}$ & $9(12)^{\mathrm{a}}$ & $29(31)$ & $6(27)$ & $20(8)^{a}$ \\
\hline$\geq 2$ sinus infections & $21(16)$ & $23(5)^{a}$ & $3(4)^{\mathrm{a}}$ & $14(15)$ & $3(9)$ & $3(1)^{a}$ \\
\hline Persistent thrush & $5(4)$ & $63(15)^{\mathrm{a}}$ & $4(6)$ & $2(2)$ & 0 & $57(24)^{\mathrm{a}}$ \\
\hline Intravenous antibiotics & $56(42)$ & $241(56)^{\mathrm{a}}$ & $60(82)^{a}$ & $41(45)$ & $10(46)$ & $129(53)$ \\
\hline$\geq 2 \mathrm{mo}$ of oral antibiotics with little effect & $3(2)$ & $75(17)^{\mathrm{a}}$ & $20(27)^{\mathrm{a}}$ & $14(15)$ & $2(9)$ & $38(18)^{\mathrm{a}}$ \\
\hline Failure to thrive & 7 (3) & $135(31)^{\mathrm{a}}$ & $20(27)^{\mathrm{a}}$ & $9(10)$ & 0 & $106(44)^{\mathrm{a}}$ \\
\hline
\end{tabular}

a $P<.01$ using $\chi^{2}$ analysis comparing children with a definable and no definable PID.

TABLE 4 Specific Warning Signs That Most Strongly Correlate With Risk of PID Compared With no PID

\begin{tabular}{|c|c|c|c|c|c|}
\hline & Definable PID & Neutrophil PID & B Lymphocyte & Complement & T Lymphocyte \\
\hline Positive family history & $18(8-45)$ & $66(16-281)$ & $8(3-22)$ & $142(20-999)$ & $20(7-57)$ \\
\hline$\geq 2$ deep seated infections & NS & NS & NS & NS & $0.2(0.1-0.6)$ \\
\hline$\geq 2$ episodes of pneumonia & NS & NS & NS & NS & $0.4(0.2-0.9)$ \\
\hline Abscesses (deep skin or organ) & NS & $15(4-52)$ & NS & NS & NS \\
\hline Multiple acute otitis media & $0.5(0.3-0.8)$ & NS & NS & NS & $0.3(0.1-0.6)$ \\
\hline$\geq 2$ sinus infections & $0.3(0.1-0.7)$ & NS & NS & NS & $0.0(0.0-0.2)$ \\
\hline Persistent thrush & NS & NS & NS & NS & $3(1.1-10)$ \\
\hline Intravenous antibiotics & NS & $5(1.4-15)$ & NS & NS & NS \\
\hline$\geq 2$ mo of oral antibiotics with little effect & $14(4-23)$ & $16(2-125)$ & $11(2-48)$ & NS & NS \\
\hline Failure to thrive & $9(4-23)$ & $13(3-53)$ & NS & NS & $22(8-60)$ \\
\hline
\end{tabular}

Shown is the relative risk ( $95 \%$ confidence interval) compared with the group of children with no definable PID (Iogistic regression analysis) $(P<.01$ for all relative risk ratios shown). NS indicates not significant.

tibiotics to treat bacterial infections in identifying children with neutrophils PID and failure to thrive in children with T-lymphocyte PID. Using these 3 signs, $96 \%$ of patients with neutrophil and complement PID and $89 \%$ of children with T-lymphocyte PID could be correctly identified (Fig 1). Of the remaining 29 children in the latter group, 12 had DiGeorge syndrome and could be identified by asking about congenital anomalies, which led to an overall pick-up rate in this group of $93 \%$. Family history was the only 1 of the 10 warning signs to significantly distinguish children with B-lymphocyte PID from those with no PID.

\section{DISCUSSION}

Our results provide a simple evidence-based schema for identifying children with PID; until now, guidelines have relied largely on expert opinion. ${ }^{5}$ Because our data dem- onstrate that $95 \%$ of children with PID are referred by hospital pediatricians and 1 of the key warning signs is the need for intravenous antibiotics to treat sepsis, it seems logical to focus on educating physicians rather than the general public to ensure that children with PID are diagnosed in a timely fashion. ${ }^{7}$ Indeed, the success of a physician-focused awareness program in central and eastern Europe (J Project) is clearly illustrated by the exponential increase in the incidence of patients with PID followed up between 2004 and 2007 (from tens to thousands of patients). ${ }^{8}$

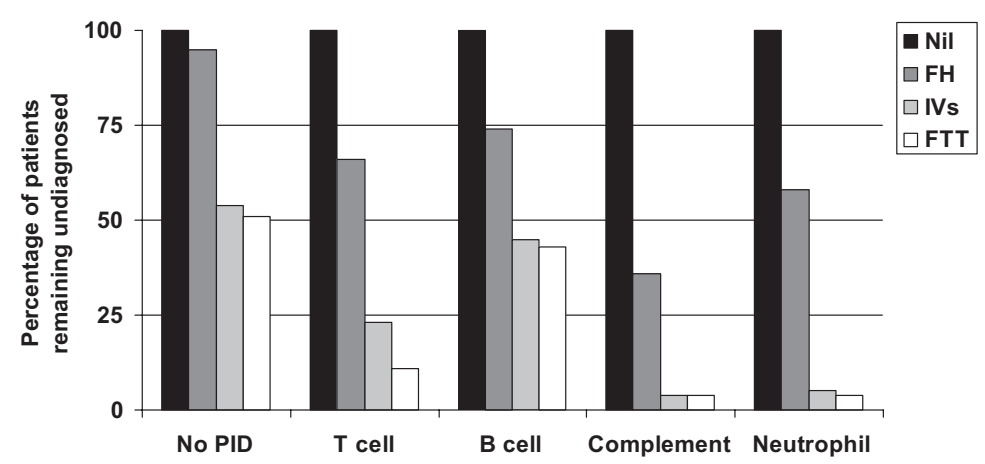

FIGURE 1

Minimal clinical criteria for identifying children with PID that affect T cells, B cell, complement, and neutrophils. Shown is the percentage of patients who remained undiagnosed after taking into account family history of PID (FH), use of intravenous antibiotics to treat infection (IVs), and failure to thrive (FTT). Percentage of children remaining in the "no PID" group are given for comparison. 
We also found that a positive family history is the key warning sign of PID. In addition to educating hospital-based pediatricians, families of children with PID should receive genetic counseling and understand the importance of screening all subsequent children soon after birth if unnecessary morbidity and mortality are to be avoided. Particularly in PID with an autosomal recessive basis, parental consanguinity is important. Countries with high rates of consanguinity - such as north and sub-Saharan Africa, the Middle East, and west, central, and south Asia-are likely to have a higher prevalence. ${ }^{9}$ For example, in Egypt, ${ }^{10} \mathrm{Ku}$ wait, ${ }^{11}$ and Iran, ${ }^{12}$ where more than half of the parents are second cousins or even more closely related, studies have highlighted the link between consanguinity and PID. Regional variation in the prevalence of PID also occurs within countries. An example is the higher prevalence of PID in ethnic Turks living in northwestern Iran..$^{13} \mathrm{~A}$ northwestern England PID database set up in 2002 and incorporating prospective information of all patients seen in the 2 tertiary PID centers, found a threefold higher prevalence of defined PID (1 per 3600 children) than in the United Kingdom as a whole (unpublished data). This northwest area is home to $25 \%$ of total Asians from the Indian Subcontinent living in England, and $>50 \%$ of the parents from this ethic group are in first-cousin marriages. ${ }^{14}$

Pediatricians managing children with infectious diseases, particularly infants and young children needing intravenous antibiotics for sepsis, should inquire about a family history of PID. Physicians caring for infants who also have congenital anomalies or failure to thrive should specifically exclude T-lymphocyte PID.

Public awareness campaigns have undoubtedly had a major impact on the burden of some diseases, ${ }^{15}$ including

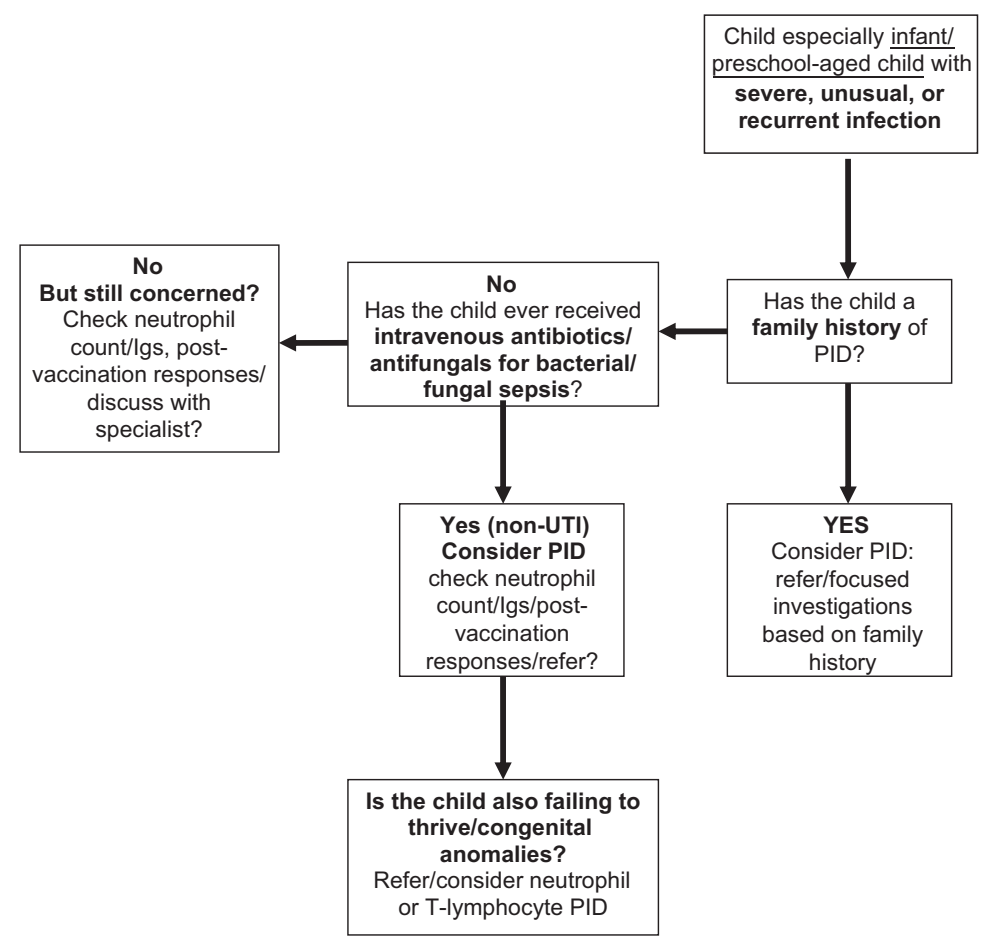

FIGURE 2

A simple schema for identifying primary immunodeficiency diseases in children with severe, unusual, or recurrent infections. Note that this flow diagram is not all-inclusive; if a clinician has concerns, he or she should refer the patient to a specialist in pediatric immunology. Igs indicates immunoglobulins; UTI, urinary tract infection.

relatively rare diseases such as sudden infant death syndrome. ${ }^{16}$ However, these public awareness campaigns regarding PID should not take priority over targeting general pediatricians and families with other children suffering from PID if the overall burden of PID is to be reduced. ${ }^{17}$

The simple schema in Fig 2 allows for the diagnosis of $\sim 90 \%$ of T lymphocyte, complement, and neutrophil or monocytic PID. Using clinical signs alone, patients with B-lymphocyte PID are more difficult to differentiate from those with normal immunity. Thus, a lower threshold is required to initiate laboratory investigations or referral to specialists where antibody immunodeficiencies are in the differential diagnosis. Laboratory screening tests for PID subtypes are listed in Table 5. If a diagnosis of PID is made, or where there is ongoing clinical concern about the possibility of such a diagnosis, the
TABLE 5 Nonpediatric Immunologists' Guide to Screening Tests for PID Subgroups

\begin{tabular}{|c|c|}
\hline $\begin{array}{c}\text { Primary } \\
\text { Immunodeficiency }\end{array}$ & Screening Investigations \\
\hline B lymphocyte & $\begin{array}{l}\text { Serum immunoglobulins } \\
\text { Antibody responses to } \\
\text { vaccinations (tetanus) } \\
\text { Lymphocyte subsets }\end{array}$ \\
\hline Neutrophil & $\begin{array}{l}\text { Full blood count (absolute } \\
\text { neutrophil count) and film } \\
\text { Neutrophil oxidative burst } \\
\text { test }\end{array}$ \\
\hline Complement & $\begin{array}{l}\text { Complement hemolyzing } 50 \% \\
\text { activity }\left(\mathrm{CH}_{50}\right) \\
\text { Complement alterative } \\
\text { pathway } 100 \% \text { activity } \\
\left(\mathrm{AP}_{100}\right)\end{array}$ \\
\hline T lymphocyte & $\begin{array}{l}\text { Full blood count } \\
\text { (absolute lymphocyte } \\
\text { count) } \\
\text { Lymphocyte subsets }\end{array}$ \\
\hline
\end{tabular}

If considering more complex tests, refer the patient to a pediatric immunologist.

attending physician should refer the child to a pediatric immunologist for further assessment or shared care. Universal newborn screening pro- 
grams using T-cell receptor excision circle for SCID have recently been developed ${ }^{18,19}$ and implemented in pilot schemes in the United States. ${ }^{20-22} \mathrm{Al}$ though newborn screening technology may detect children with SCID, it does not currently identify children with the remaining $>120$ PID that can also be life-threatening or life-limiting but are not associated with low T-cell receptor excision circle values. ${ }^{23}$

No clinical guidelines can be allinclusive. At least $4 \%$ of children with PID will be missed even if the recommendations made in this study are followed. Our knowledge of the spectrum of PID has expanded over the last 2 decades. ${ }^{23}$ It is increasingly recognized that specific PID predispose to the development of not only infectious dis-

\section{REFERENCES}

1. Joshi AY, Iyer VN, Hagan JB, St Sauver JL, Boyce TG. Incidence and temporal trends of primary immunodeficiency: a populationbased cohort study. Mayo Clin Proc. 2009; $84(1): 16-22$

2. Gathmann B, Grimbacher B, Beauté J, et al. The European internet-based patient and research database for primary immunodeficiencies: results 2006-2008. Clin Exp Immunol. 2009; 157 (suppl 1):3-11

3. Fischer A. Human primary immunodeficiency diseases. Immunity. 2007;27(6): 835-845

4. Maródi L, Notarangelo LD. Immunological and genetic bases of new primary immunodeficiencies. Nat Rev Immunol. 2007;7(11): 851-861

5. INF04PI.org. Primary immunodeficiency resource center. Available at: www.info4pi. org. Accessed March 14, 2011

6. Primary Immunodeficiency Association. Publications: 10 warning signs of a primary immunodeficiency. Available at: www.pia. org.uk/publications/10_signs_of_pia/10_ signs_01.htm. Accessed March 14, 2011

7. Banks M. Deficient diagnosis. Parliament Magazine. May 3, 2010:24-26

8. Maródi L, Casanova JL. Primary immunodeficiency diseases: the $\mathrm{J}$ project. Lancet. 2009;373(9682):2179-2181

9. Bittles AH, Black ML. Evolution in health and medicine Sackler colloquium: consanguinity, human evolution, and complex diseases. eases but also inflammatory, autoimmune, allergic, and neoplastic conditions, particularly in infants and young children. ${ }^{24,25}$ Severe, recurrent, or unusual infections are thus not the only clinical presentation in which PID needs to be considered in the differential diagnosis. Optimizing detection and management of children with PID requires that pediatricians, particularly those working in hospitals, remain vigilant to the possibility that children who present with these conditions may have an underlying immunodeficiency.

\section{CONCLUSIONS}

Delayed diagnosis of PID may be associated with increased morbidity and mortality. Pediatricians refer the majority of children with PID to specialist services

Proc Natl Acad Sci U S A. 2010;107(suppl 1):1779-1786

10. Reda SM, Afifi HM, Amine MM. Primary immunodeficiency diseases in Egyptian children: a single-center study. J Clin Immunol. 2009;29(3):343-351

11. Al-Herz W, Naguib KK, Notarangelo LD, Geha RS, Alwadaani A. Parental consanguinity and the risk of primary immunodeficiency disorders: report from the Kuwait National Primary Immunodeficiency Disorders Registry. Int Arch Allergy Immunol. 2011;154(1): 76-80

12. Rezaei N, Pourpak Z, Aghamohammadi A, et al. Consanguinity in primary immunodeficiency disorders; the report from Iranian Primary Immunodeficiency Registry. Am J Reprod Immunol. 2006;56:145-151

13. Shabestari MS, Maljaei SH, Baradaran R, et al. Distribution of primary immunodeficiency diseases in the Turk ethnic group, living in the northwestern Iran. J Clin Immunol. 2007;27 (5):510-516

14. Darr A, Modell B. The frequency of consanguineous marriage among British Pakistanis. J Med Genet. 1988;25(3):186-190

15. Arkin EB. Opportunities for improving the nation's health through collaboration with the mass media. Public Health Rep. 1990; 105(3):219-223

16. Wigfield R, Gilbert R, Fleming PJ. SIDS: risk reduction measures. Early Hum Dev. 1994; 38(3):161-164 for specific diagnosis and treatment. On the basis of our analysis, we found 3 warning signs, rather than 10 , that are most important in identifying children with PID. In children presenting with infection, pediatricians should always inquire about a family history of PID, as this is the best predictor that the patient may also have an underlying immunodeficiency. PID, particularly neutrophil defects, should be considered in children requiring intravenous antibiotics for sepsis. In children with infections, failure to thrive should suggest the possibility of a T-cell immunodeficiency. In those with recurrent or severe infections, clinical features other than family history are often not helpful and a lower threshold is required for requesting antibody testing in which the diagnosis of a B-cell immunodeficiency is suspected.

17. Waltenburg R, Kobrynski L, Reyes M, Bowen S, Khoury MJ. Primary immunodeficiency diseases: practice among primary care providers and awareness among the general public, United States, 2008. Genet Med. 2010; 12(12):792-800

18. US Department of Health and Human Services, Health Resources and Services Administration, Advisory Committee on Heritable Disorders in Newborns and Children. Letter to the Secretary, U.S. Department of Health and Human Services, February 25, 2010. Available at: www. hrsa.gov/heritabledisorderscommittee/ correspondence/feb2010letter.htm. Accessed December 18, 2010

19. Lipstein EA, Vorono S, Browning MF, et al. Systematic evidence review of newborn screening and treatment of severe combined immunodeficiency. Pediatrics. 2010; 125(5). Available at: www.pediatrics.org/ cgi/content/full/125/5/e1226

20. Chase NM, Verbsky JW, Routes JM. Newborn screening for T-cell deficiency. Curr Opin Allergy Clin Immunol. 2010;10(6):521-525

21. Comeau AM, Hale JE, Pai SY, et al. Guidelines for implementation of population-based newborn screening for severe combined immunodeficiency. J Inherit Metab Dis. 2010;33(suppl 2):S273-S281

22. Janik DK, Lindau-Shepard B, Comeau AM, Pass KA. A multiplex immunoassay using Guthrie specimen to detect T-cell deficiencies includ- 
ing severe combined immunodeficiency disease. Clin Chem. 2010;56(9):1460-1465

23. Geha RS, Notarangelo LD, Casanova JL, et al; International Union of Immunological Societies Primary Immunodeficiency Disease Classification Committee. Primary immuno- deficiency diseases: an update from the International Union of Immunological Societies Primary Immunodeficiency Diseases Classification Committee. J Allergy Clin Immunol. 2007;120(4):776-794

24. Casanova JL, Abel L. Primary immuno- deficiencies: a field in its infancy. Science. 2007;317(5838):617-619

25. Maródi L, Casanova JL. Novel primary immunodeficiencies relevant to internal medicine: novel phenotypes. J Intern Med. 2009;266(6):502-506 


\section{Clinical Features That Identify Children With Primary Immunodeficiency Diseases}

Anbezhil Subbarayan, Gloria Colarusso, Stephen M. Hughes, Andrew R. Gennery, Mary Slatter, Andrew J. Cant and Peter D. Arkwright

Pediatrics published online Apr 11, 2011;

DOL: $10.1542 /$ peds. 2010-3680

Updated Information

\& Services

Permissions \& Licensing

Reprints including high-resolution figures, can be found at:

http://www.pediatrics.org

Information about reproducing this article in parts (figures, tables) or in its entirety can be found online at:

http://www.pediatrics.org/misc/Permissions.shtml

Information about ordering reprints can be found online:

http://www.pediatrics.org/misc/reprints.shtml

\section{American Academy of Pediatrics}

